\title{
O Estudo das Instituições Políticas na Ciência Política Brasileira: Uma Análise da Produção Acadêmica (1966-2014)
}

\section{The Study of Political Institutions in Brazilian Political Science: An Analysis of Academic Production (1966-2014)}

Lilian Oliveira $^{1}$

\section{INTRODUÇÃO}

As instituições políticas formam uma das principais áreas temáticas da ciência política, desde o início de sua trajetória. Nos Estados Unidos, por exemplo, país pioneiro na institucionalização acadêmica da disciplina, a importância da análise das instituições vem de longa data e pode ser atribuída à influência inicial da tradição jurídica, que via nas regras formais o motor dos fenômenos políticos. Nessas primeiras décadas, um grande volume de estudos sobre as instituições foi produzido, e esses estudos deram origem ao movimento teórico intitulado institucionalismo, cuja influência perpassa toda a trajetória da disciplina, tanto a norte-americana quanto a de outros países (Easton, 1985; Munck e Snyder, 2007; Pierson, 2007).

No Brasil, as instituições políticas passaram a constituir uma área consolidada de estudos da ciência política na segunda metade da década de 1990. Estimulados pela retomada democrática no final dos anos 1980 e pelas novas configurações institucionais que se seguiram, um expressivo contingente de cientistas políticos voltou-se para o estudo do desenho institucional adotado e para os seus impactos nos resultados políticos. Deve-se considerar também a influência exercida pela ciência política norte-americana, que experimentava, desde meados dos nos 1980, a retomada dos estudos institucionalistas. Além disso, há que ressaltar outro elemento impulsionador dessa onda de estudos: a necessidade de responder às análises pessimistas sobre o cenário político do país feitas por alguns estudiosos brasileiros e estrangeiros, que apontavam para a falência da engenharia institucional aqui adotada.

\footnotetext{
${ }^{1}$ Doutora em ciência política pelo IESP/UERJ, onde defendeu a tese "A Trajetória da ciência política brasileira: Uma análise da produção e da formação acadêmica (1966-2014)”, em 2016. É bolsista de pósdoutorado júnior do CNPq na UFRJ.
} 
No entanto, em que pesem quase duas décadas de estudos sobre as instituições políticas, ainda são poucos os trabalhos que se dedicaram à sua sistematização, podendo-se destacar balanços bibliográficos sobre algumas das suas subáreas, tais como o Legislativo, o Executivo e os partidos políticos (Figueiredo, 2010; Limongi, 2010; Nicolau, 2010; Santos, 2008). Sendo assim, o objetivo deste artigo é realizar uma análise mais detida dos estudos sobre as instituições políticas na ciência política brasileira. Para tanto, foram analisados os trabalhos publicados, entre os anos de 1966 e 2014, por cientistas políticos brasileiros em cinco revistas acadêmicas de ciências sociais editadas no Brasil: DADOS - Revista de Ciências Sociais, Novos Estudos, Revista Brasileira de Ciências Sociais (RBCS), Opinião Pública e Brazilian Political Science Review (BPSR).

Além desta introdução, o artigo está organizado da maneira que se segue: a primeira seção apresenta a pesquisa e os dados analisados, ao passo que a segunda exibe e discute os resultados encontrados. Por fim, a terceira seção enumera as conclusões do trabalho, destacando as principais características dos estudos sobre as instituições políticas na ciência política brasileira.

\section{SOBRE A PESQUISA}

Para a análise dos estudos sobre as instituições políticas, optei por examinar os artigos publicados pelos cientistas políticos brasileiros em revistas acadêmicas. Mesmo em face da não exclusividade dos artigos como meios de divulgação do trabalho científico, a escolha por esse tipo de publicação deve-se a alguns fatores: o prestígio das revistas junto à comunidade acadêmica; o caráter científico desses meios de difusão (avaliação por pares); o fato de as revistas serem indicadores de qualidade para os órgãos de avaliação da pós-graduação brasileira, entre outros. Embora se tenha em mente que os cientistas políticos brasileiros também publicam os resultados de suas pesquisas em periódicos estrangeiros, foram analisadas apenas revistas nacionais, por dois motivos: a ênfase na disciplina brasileira e a facilidade no acesso aos artigos.

Uma vez que o foco da pesquisa se volta para a produção da ciência política brasileira, selecionei apenas os artigos escritos por autores que se identificaram como cientistas políticos e que possuíam nacionalidade brasileira (no caso de autores estrangeiros, deveriam trabalhar e residir no Brasil). Mesmo atendendo a esses critérios, alguns trabalhos foram excluídos da análise por não se tratar de artigos acadêmicos, tais como 
obituários, resenhas, transcrição de conferências e textos de opinião ou análises de conjuntura.

O período analisado se estende entre os anos de 1966 e 2014, cobrindo toda a trajetória da ciência política brasileira como disciplina institucionalizada. O ano de 1966 é considerado um marco desse processo, dada a criação do primeiro programa de pósgraduação em ciência política no Brasil, na UFMG. Além disso, nesse ano também foi publicado o primeiro número da revista $D A D O S$, outro evento importante para a sua história institucional.

$\mathrm{O}$ acesso aos artigos deu-se em páginas na internet, tanto das próprias revistas quanto da plataforma Scielo, ou em edições impressas ou digitalizadas disponíveis em CD-ROM. As informações sobre os autores, quando não constavam nas revistas, foram retiradas dos currículos dos pesquisadores disponíveis na plataforma Lattes. Os artigos que se enquadravam nos critérios de inclusão no banco foram classificados de acordo com variáveis que dizem respeito aos autores e ao conteúdo do trabalho. Os dados coletados foram analisados por meio de estatísticas descritivas simples (média, frequência e cálculo de percentual). A lista das variáveis utilizadas para classificar os artigos, bem como a descricão de cada uma delas, encontra-se no Anexo, localizado ao final do texto.

\section{RESULTADOS}

Nos 46 anos cobertos pela pesquisa, foram classificados 919 artigos. Deste total, 25\% tinham como foco principal o estudo de uma instituição política. Em seguida aparecem as áreas de eleições e comportamento político e teoria e história do pensamento político, com $20 \%$ e $19 \%$ de participação, respectivamente, além das áreas de políticas públicas (15\%) e atores políticos (14\%). Por fim aparecem as áreas com participação residual nas revistas analisadas: estrutura social, relações internacionais, entre outras.

Em relação aos veículos de divulgação dos artigos sobre instituições políticas, $70 \%$ deles foram publicados nas revistas DADOS e RBCS. Essas são as revistas mais antigas e, de modo geral, publicaram um maior número de artigos em quase todas as áreas temáticas. No entanto, quando se analisa a produção de cada periódico, percebe-se um padrão 
diferente. A Figura 1 apresenta a distribuição dos trabalhos sobre instituições políticas entre o total da produção de cada uma das cinco publicações analisadas ${ }^{2}$.

\section{Figura 1}

\section{Artigos por Área Temática e por Periódico (\%)}

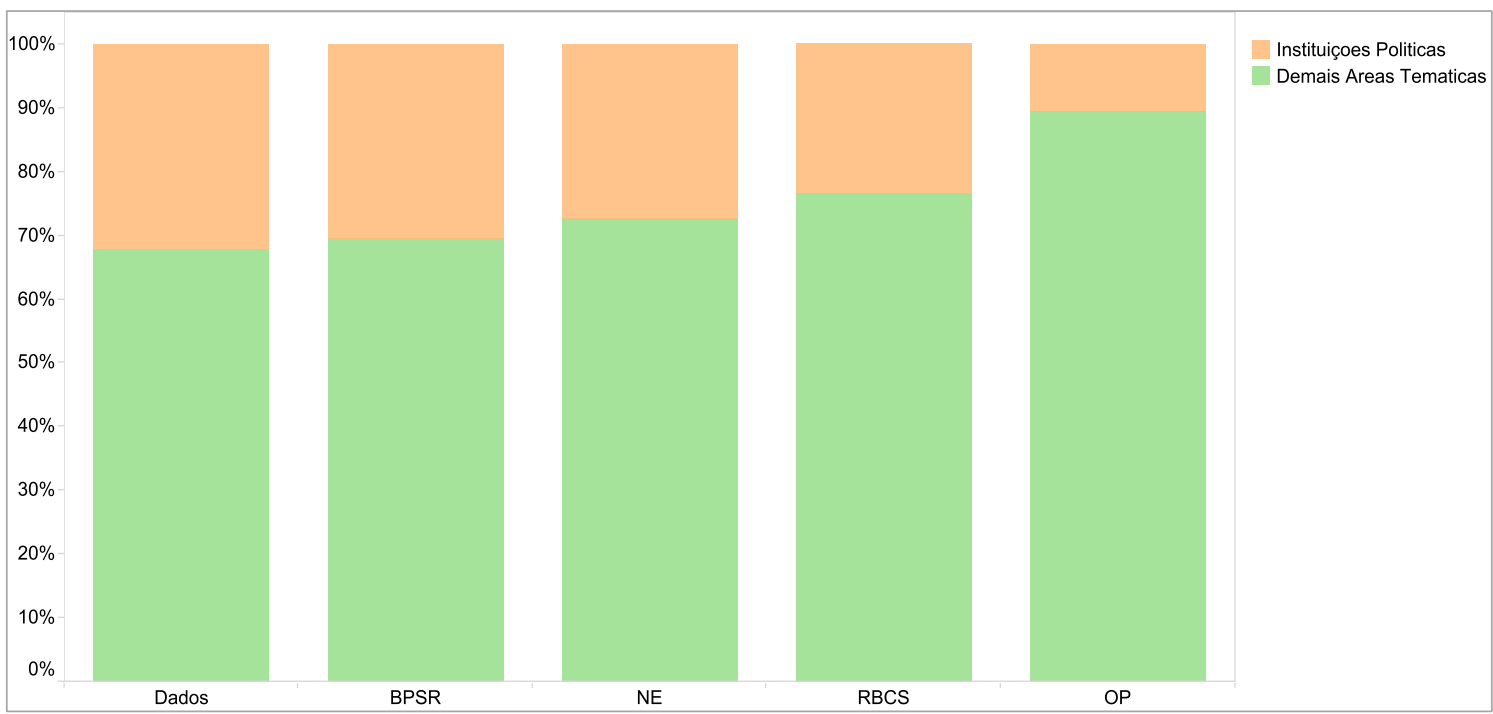

Notas: 1) $\mathrm{N}=919.2$ ) A figura ilustra a distribuição, em percentual, do total de artigos publicados em cada periódico (Dados: 370; RBCS: 205; Opinião Pública: 169; Novos Estudos: 106 e BPSR: 69) pelos artigos sobre instituições políticas e demais áreas temáticas.

Fonte: Elaboração própria.

Considerando-se a produção de cada periódico, o protagonismo fica entre as revistas DADOS e BPSR, seguidas de perto pela Novos Estudos. Quanto à RBCS, mesmo publicando um expressivo número de artigos, as instituições políticas equivalem a menos de 1/4 do total de sua produção. Por fim, a revista Opinião Pública, mesmo sendo uma publicação voltada quase que exclusivamente para a disciplina, é a que possui o menor percentual de artigos dessa área temática, o que talvez possa ser explicado pelo fato de o periódico ser vinculado ao Centro de Estudos de Opinião Pública (CESOP), centro de pesquisa sobre opinião pública, eleições e comportamento político que privilegia outras áreas da ciência política que não a de instituições.

\footnotetext{
${ }^{2}$ Aqui o total de $100 \%$ refere-se ao número de artigos publicados em cada revista.
} 
É interessante frisar que a proeminência dos estudos sobre as instituições políticas na ciência política brasileira só se fez notar após três décadas de institucionalização acadêmica da disciplina. Como mostra a Figura 2, foi somente a partir da segunda metade da década de 1990 que os estudos institucionais ganharam notoriedade na produção dos cientistas políticos, experimentando um constante aumento desde então.

Figura 2

Instituições Políticas por Período (\%)

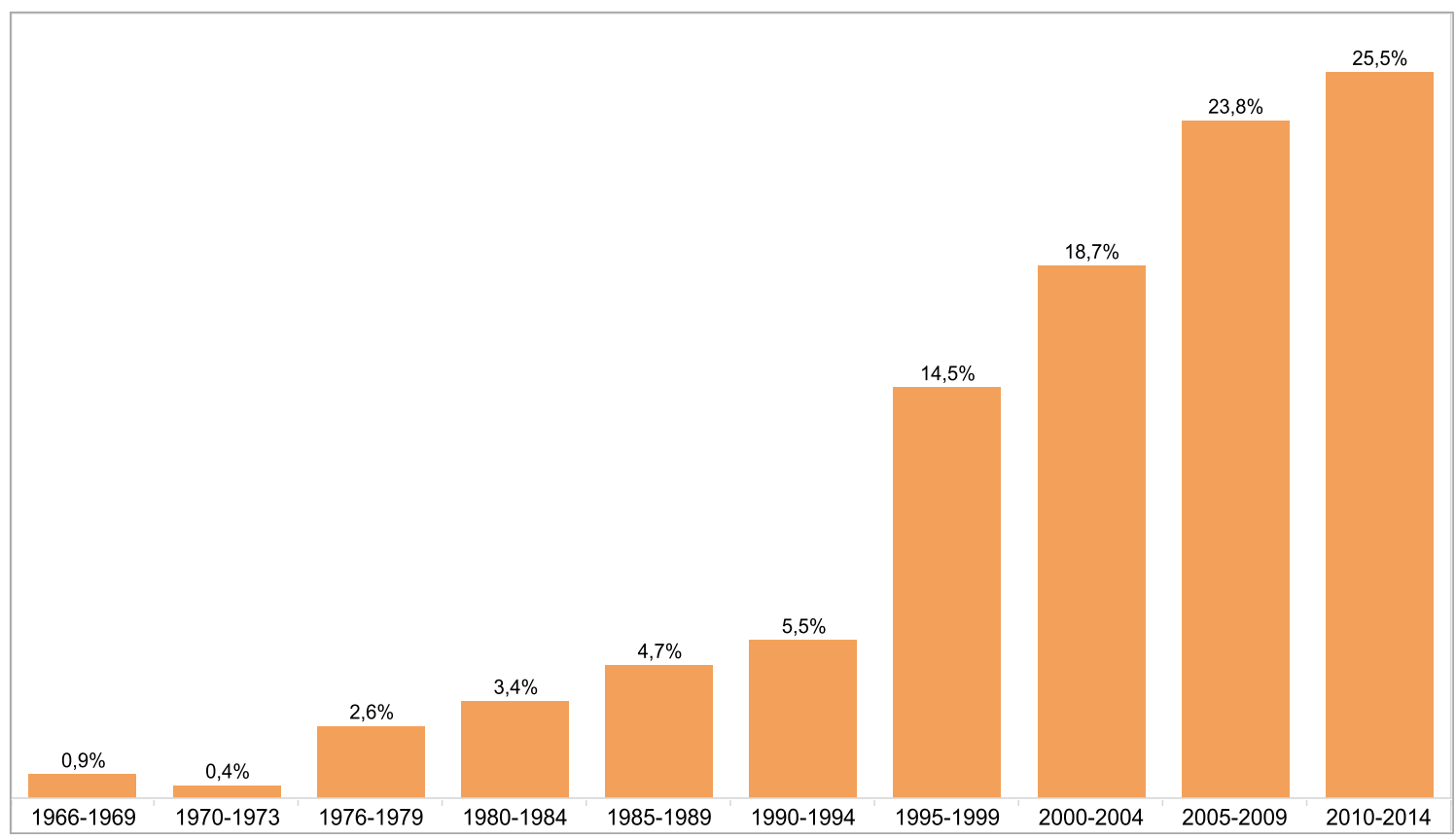

Notas: 1) $\mathrm{N}=235$. 2) A figura ilustra o percentual dos artigos sobre instituições políticas entre o total de trabalhos publicados em cada período. Cada segmento agrega cinco anos, com exceção dos três primeiros, que agregam quatro anos.

Fonte: Elaboração própria.

A preponderância das instituições políticas a partir da década de 1990 pode ter duas explicações, uma intelectual e outra contextual. A explicação intelectual tem a ver com as orientações teóricas que teriam exercido influência no Brasil. A partir de meados dos anos 1980, a ciência política, sobretudo a norte-americana, vivenciou a retomada dos estudos sobre as instituições políticas. Com a agenda neoinstitucionalista, foi recuperada a centralidade das instituições políticas para os resultados políticos. A incorporação 
desses pressupostos pelos cientistas políticos brasileiros pode explicar a predominância dos estudos sobre instituições.

Já a explicação contextual tem a ver com as mudanças políticas ocorridas no país nos últimos 50 anos. A ciência política brasileira iniciou seu processo de institucionalização simultaneamente ao Regime Militar. Nesse período, os partidos não agiam livremente, o Legislativo funcionava sob restrições, e as eleições, embora permitidas para alguns cargos, não eram livres e competitivas, existindo limitações para os estudos institucionalistas. A abertura democrática e a consolidação das instituições brasileiras impulsionaram esses estudos entre os praticantes da disciplina, que passava ela mesma por um período de crescimento e amadurecimento intelectual.

Mas os diferentes tipos de instituições políticas importam de igual maneira para a ciência política brasileira? Como mostra a Figura 3, existe uma forte concentração em duas subáreas: Legislativo (e sua relação com o Executivo) e os partidos políticos (e sistemas partidários), que correspondem a 54\% do total de artigos sobre instituições políticas. O restante da produção está distribuído entre as demais subáreas: Federalismo (e descentralização), Judiciário, Democracia, Sistema Eleitoral (e reforma política) e Executivo $^{3}$.

Figura 3

\section{Artigos por Tipos de Instituições Políticas (\%)}

\footnotetext{
${ }^{3}$ As demais subáreas são residuais e aparecem em menos de 5\% dos artigos: Constituição, Transição de Regime, Ditadura, Presidencialismo, República e outros (artigos que não se enquadravam nas categorias existentes nem apareciam em quantidade suficiente para justificar a inclusão de nova categoria).
} 


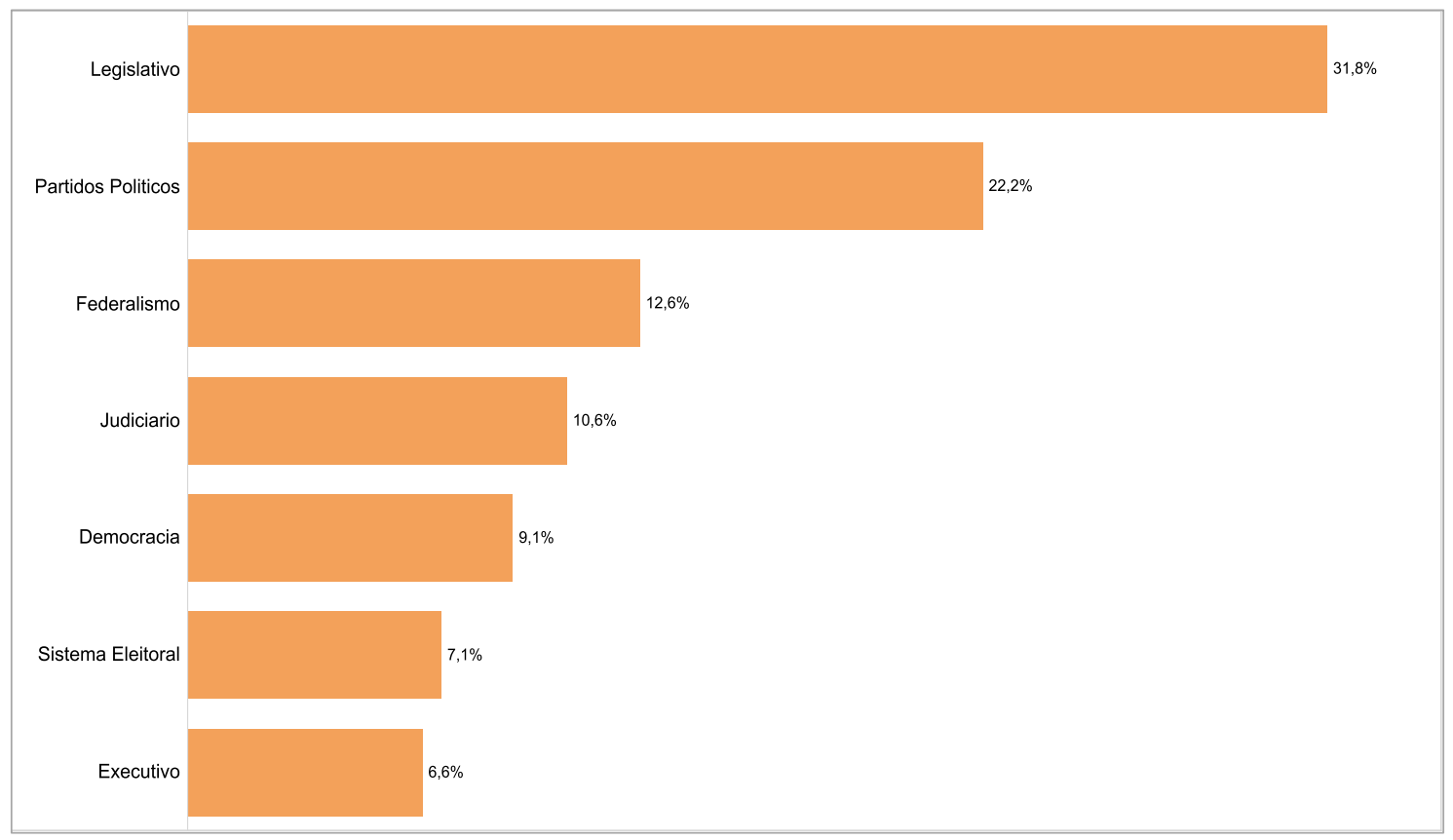

Notas: 1) $\mathrm{N}=198$. 2) A figura ilustra a distribuição, em percentual, dos artigos classificados nessa área temática entre os principais tipos de instituições políticas.

Fonte: Elaboração própria.

Esses resultados corroboram as avaliações feitas por Figueiredo (2010), Limongi (2010) e Nicolau (2010) a respeito dos estudos de algumas instituições políticas. Como mostraram esses autores, os estudos legislativos e partidários são de longe os mais recorrentes, ao passo que o poder Executivo é preterido nas análises, estando na maioria das vezes vinculado aos estudos sobre a sua relação com o Legislativo. Cabe destacar também a participação expressiva dos trabalhos sobre o Federalismo e sobre o Judiciário. Os primeiros, em geral, estão associados aos estudos sobre os impactos que as normas de distribuição dos bens públicos (sobretudo o orçamento da União) têm sobre as relações entre os entes federados, ao passo que os trabalhos sobre o poder Judiciário são comumente voltados para o protagonismo político dos magistrados, especialmente os do Supremo Tribunal Federal.

Uma análise mais detida da distribuição de cada tipo de instituição no tempo mostra que esse quadro geral mudou bastante no período analisado. Pelo que ilustra a Figura 4, até a primeira metade da década de 1990 a produção sobre instituições políticas era reduzida, e havia uma menor variabilidade nos tipos de instituições estudadas. Nesta fase, concomitante ao regime militar, foram os estudos sobre a democracia (transição e 
modelos de regime democrático) e partidos políticos e sistemas partidários que tiveram maior participação.

\section{Figura 4}

Tipos de Instituições Políticas por Período (\%)

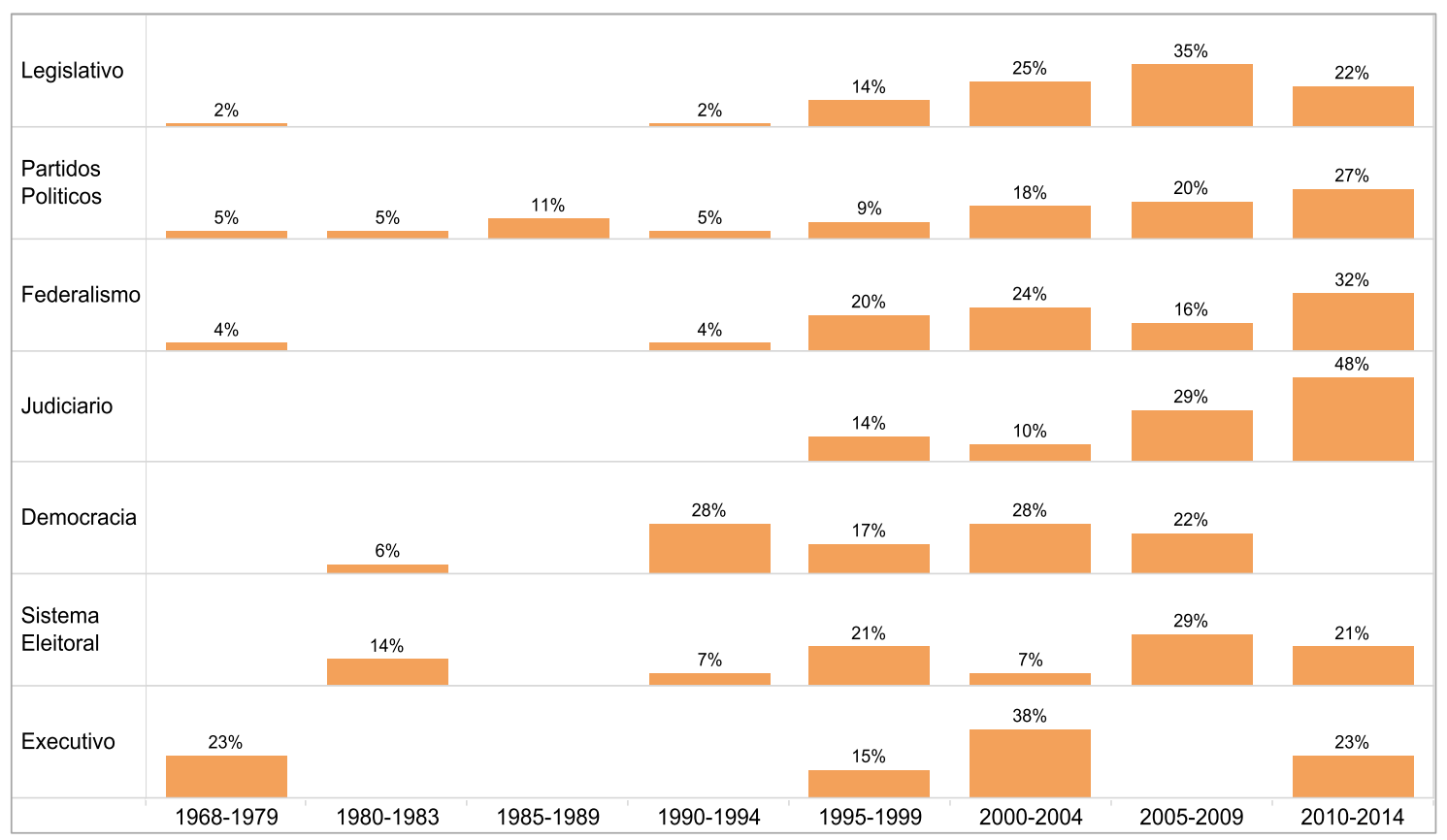

Notas: 1) $\mathrm{N}=198$. 2) A figura ilustra a distribuição, em percentual, do total de artigos sobre instituições políticas publicados em cada período entre as principais subáreas.

Fonte: Elaboração própria.

É interessante observar que na segunda metade da década de 1980, marcada pelo período de abertura do regime ditatorial, os estudos sobre os partidos políticos são os temas privilegiados, uma vez que, com o avanço do processo de abertura, novas agremiações partidárias surgem, dando origem a um sistema multipartidário. Cabe destacar também a relevância que os estudos sobre a democracia tiveram nos primeiros anos da retomada democrática, pois com as novas perspectivas políticas que se avizinhavam, era premente analisar o modelo de democracia adotado e quais seriam seus impactos para o sistema político brasileiro.

O avanço no processo de redemocratização e a estabilidade democrática que se seguiu, com o livre funcionamento das instituições políticas, possibilitou uma abertura do leque temático da disciplina. Como se pode verificar na Figura 4, a partir da segunda metade da década de 1990 novas instituições entram no radar de interesse dos cientistas políticos. No entanto, pode-se ainda dizer que a área de instituições políticas possui duas subáreas 
predominantes, quais sejam, os estudos legislativos e os estudos partidários, tópicos que estão substantivamente bem próximos na agenda de pesquisa dos institucionalistas.

Cabe agora averiguar os aspectos metodológicos dos estudos sobre as instituições políticas. Esses são eminentemente de natureza empírica, ou seja, utilizam dados e ferramentas de análise para a sua realização. Sua predominância, no entanto, passou a se dar somente a partir da segunda metade da década de 1990, conforme ilustra a Figura 5.

\section{Figura 5}

\section{Instituições Políticas por Tipo de Artigo e por Período (\%)}

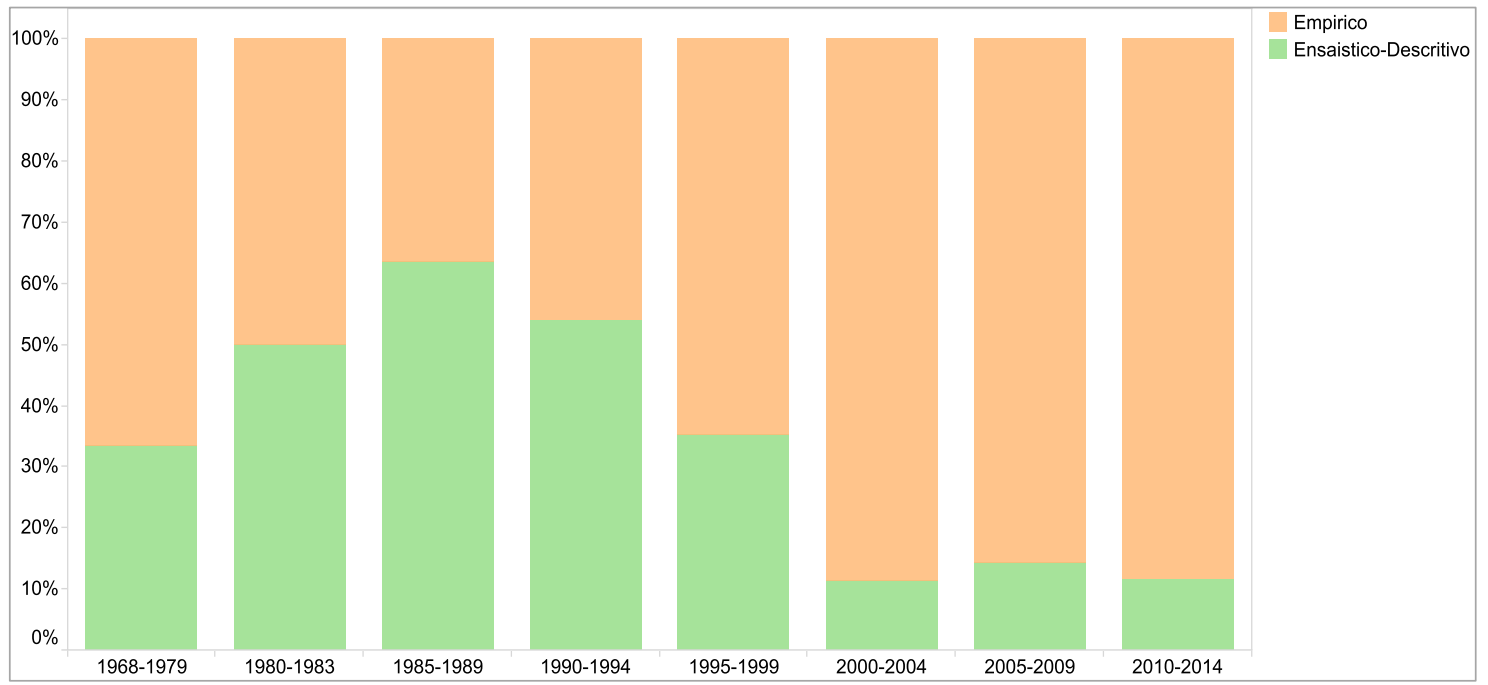

Notas: 1) $\mathrm{N}=235.2$ ) A figura ilustra a distribuição, em percentual, do total de trabalhos sobre instituições políticas por tipo de artigo.

Fonte: Elaboração própria.

É possível perceber, ao longo desses 46 anos, uma sensível mudança nos tipos de pesquisa realizados na área de instituições políticas. Se nos primeiros anos havia a predominância dos trabalhos empíricos, nas décadas seguintes esse cenário se altera e as pesquisas ensaístico-descritivas passam a orientar a maior parte dos trabalhos. Foi somente a partir de meados da década de 1990 que as pesquisas empíricas voltariam a predominar nos estudos sobre as instituições políticas. Essa mudança nas orientações metodológicas dos trabalhos acompanha um processo mais amplo ocorrido na ciência política brasileira, que pode estar relacionado ao processo mesmo de amadurecimento da disciplina. Há que se considerar também outro fator importante para essa mudança no tipo de trabalho 
realizado: com a abertura democrática, tornam-se disponíveis documentos e dados antes inacessíveis.

Esse livre acesso às informações e aos dados, característicos de um regime democrático, pode ser ilustrado pelas principais fontes utilizadas nos artigos sobre instituições políticas. Como mostra a Figura 6, as fontes mais recorrentes são as estatísticas e os documentos oficiais, presentes em $58 \%$ e $56 \%$ dos artigos, respectivamente. Em seguida aparecem as fontes secundárias $(27 \%)$ e os meios de comunicação $(11 \%)^{4}$.

\section{Figura 6}

\section{Artigos sobre Instituições Políticas por Fontes de Dados (\%)}

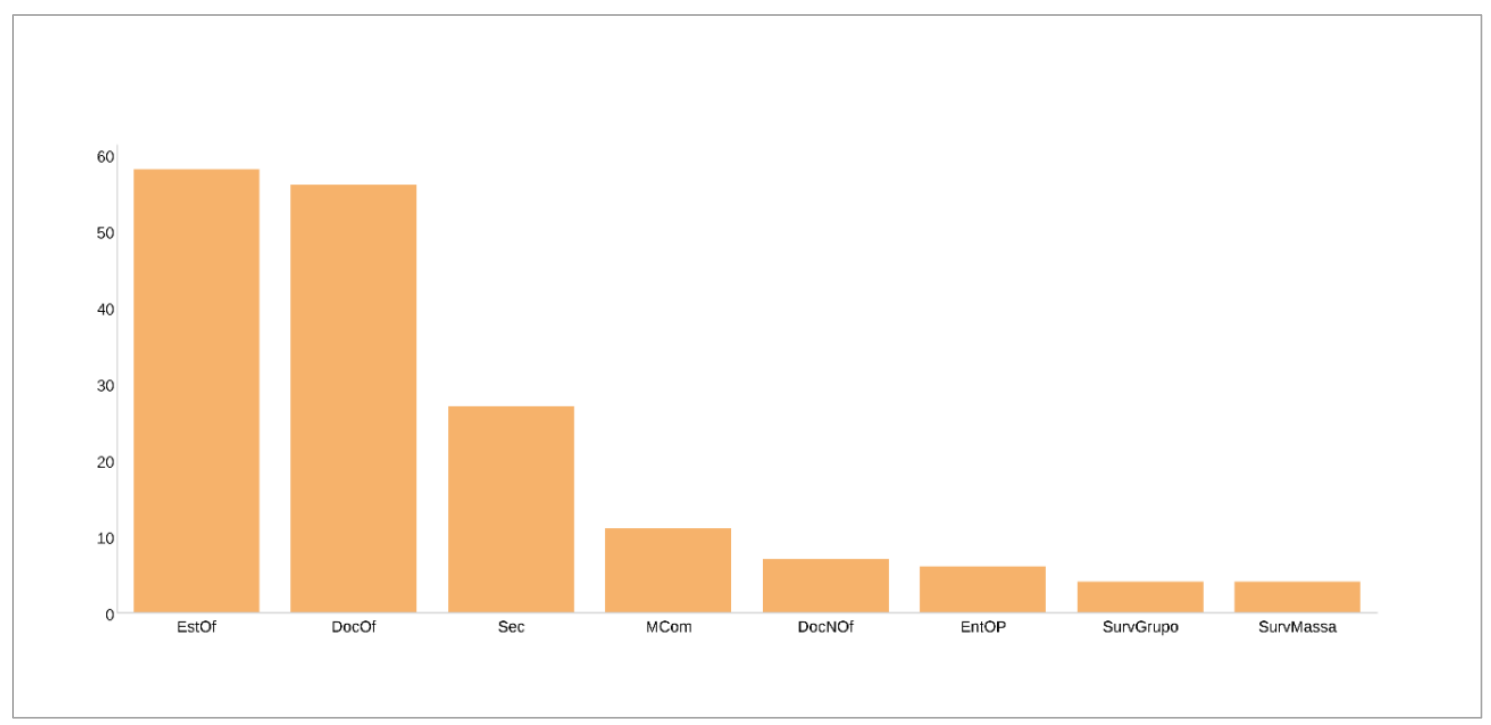

${ }^{4}$ Documentos não oficiais, entrevistas e survey têm participação residual. 
Notas: 1) $\mathrm{N}=235.2$ ) A figura ilustra a distribuição, em percentual, dos artigos sobre instituições políticas pelas principais fontes de dados utilizadas. 3) $\mathrm{O}$ total ultrapassa $100 \%$ porque um artigo pode usar mais um tipo de fonte.

Fonte: Elaboração própria.

As principais fontes de dados utilizadas estão intimamente ligadas às instituições políticas predominantes. Os estudos legislativos valem-se do texto da constituição, dos projetos de lei, das portarias e das normas regimentais, dos relatórios de votações nominais, dos boletins e circulares internos e dos dados biográficos sobre congressistas. Já os estudos sobre os partidos políticos lançam mão dos resultados eleitorais disponibilizados pelo TSE e pelos TREs, da legislação partidária, bem como dos documentos não oficiais disponibilizados pelas siglas. Vale menção ao aumento do uso das técnicas de survey nos estudos partidários da última década, que pode ser atribuído aos dados fornecidos pelo Estudo Eleitoral Brasileiro (ESEB), survey nacional realizado pelo CESOP, desde o ano de 2002, após as eleições presidenciais ${ }^{5}$.

Os instrumentos utilizados para a análise desses dados estão representados na Figura 7. As ferramentas mais recorrentes nas pesquisas empíricas são os métodos quantitativos. As estatísticas descritivas simples, como o cálculo de frequências e porcentagens, são as mais utilizadas em todo o período analisado e estão presentes em $70 \%$ dos trabalhos. No entanto, pode-se notar o crescimento do uso de outros métodos estatísticos, sobretudo a partir da segunda metade dos anos 2000. As estatísticas descritivas mais avançadas (cálculo de índices, escalas, teste de média e coeficiente de correlação) aparecem na segunda posição, com 30\% de participação. Em terceiro lugar, aparecem as técnicas de regressão (linear - simples ou múltipla - e logística), recorrentes em 17\%. As técnicas multivariadas e a análise de conteúdo têm participação modesta e aparecem em menos de $10 \%$ dos trabalhos.

\section{Figura 7}

\section{Artigos sobre Instituições Políticas por Métodos de Análise (\%)}

\footnotetext{
${ }^{5}$ Para mais informações, ver: http://www.cesop.unicamp.br/site/htm/apre.php
} 


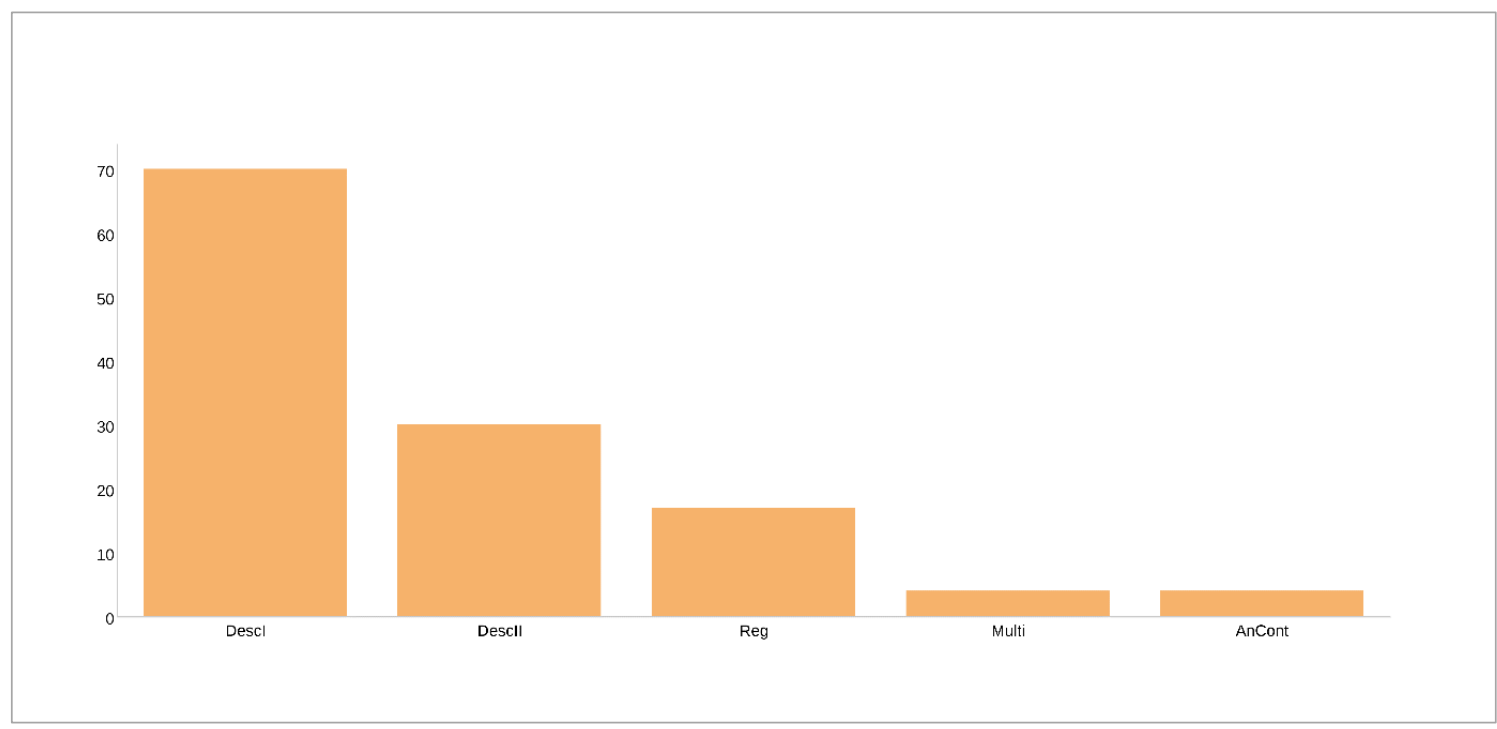

Notas: 1) $\mathrm{N}=235$. 2) A figura ilustra a distribuição, em percentual, dos artigos sobre instituições políticas pelos cinco principais métodos de análise de dados utilizados. 3) O total ultrapassa 100\% porque um artigo pode usar mais um tipo de método de análise.

Fonte: Elaboração própria.

É interessante notar que o uso dos modelos de regressão está fortemente concentrado nos artigos sobre o Legislativo (e sua relação com o Executivo): $50 \%$ dos artigos que os utilizam como métodos de análise foram classificados nessa subárea. Como verificado por Santos (2008) em sua análise sobre os estudos legislativos, essa subárea experimentou um considerável investimento metodológico nos últimos anos, o que pode explicar essa concentração do uso dos modelos de regressão. Outro fator que talvez explique essa predominância é a importância da ciência política norte-americana, que pode ter influenciado não apenas na abordagem teórica, mas também no tratamento metodológico dispensado às análises ${ }^{6}$.

Por fim, resta analisar o escopo privilegiado nas análises ${ }^{7}$. Dos 235 artigos analisados, $84 \%$ estudam as instituições políticas no âmbito doméstico. Além dessa concentração nas instituições brasileiras, existe também uma concentração nas unidades de análise. Os estudos domésticos privilegiam, em $72 \%$ dos casos, a abordagem das instituições em

\footnotetext{
${ }^{6}$ Assim como nas demais áreas da disciplina, os métodos qualitativos, como as tipologias e as análises de conteúdo, são quase inexistentes, não chegando a $5 \%$ dos artigos.

${ }^{7} \mathrm{O}$ critério para classificar o escopo dos artigos não diz respeito a questões metodológicas ou teóricas propriamente ditas. 0 critério utilizado por mim considera como escopo doméstico os artigos que incluíam apenas o Brasil nas análises, ou ainda quando citavam de maneira ilustrativa outros países, ao passo que foram classificados com escopo comparado os trabalhos que analisavam instituições políticas de outro país.
} 
âmbito nacional, ao passo que as subunidades da federação, os grupos e as organizações aparecem em menor proporção. Essa predominância na esfera federal fica mais evidente quando são analisadas as duas principais instituições políticas estudadas. Nos estudos legislativos, o Congresso (sobretudo a Câmara dos Deputados) predomina nas análises, com pouco espaço para os legislativos estaduais e municipais. O mesmo pode ser dito a respeito da segunda instituição mais estudada: nos estudos que analisam os partidos políticos, quase todos dizem respeito à atuação dos partidos na esfera nacional, tendo pouca visibilidade o modo como as agremiações se organizam e atuam nas subunidades da federação.

Em se tratando dos trabalhos feitos em perspectiva comparada, esses ainda são minoritários nos estudos sobre as instituições políticas, embora tenham se tornado mais recorrentes a partir da década de $2000^{8}$. Quanto aos temas estudados, novamente se destacam os estudos legislativos, presentes em 25\% dos artigos. Em seguida aparecem as análises sobre os sistemas eleitorais e os regimes democráticos, com $20 \%$ e $17 \%$ de participação, respectivamente. Quanto às regiões do mundo analisadas, a Figura 8 mostra como elas estão distribuídas entre os trabalhos comparativos.

\section{Figura 8}

\section{Artigos sobre Instituições Políticas em Perspectiva Comparada por Região (\%)}

\footnotetext{
${ }^{8}$ No entanto, os estudos sobre as instituições políticas correspondem a $42 \%$ do total de artigos com abordagem comparativa na produção da ciência política brasileira.
} 


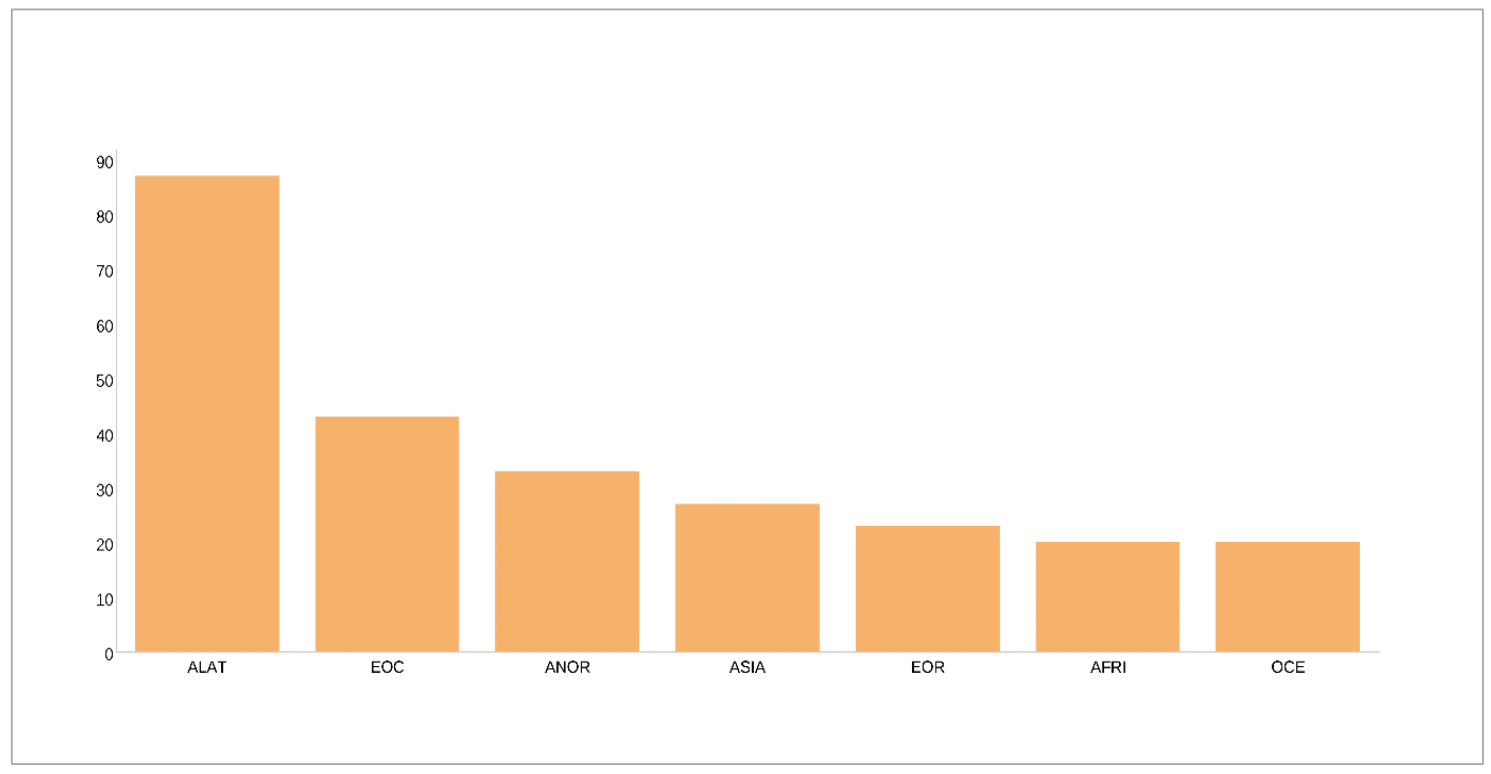

Notas: 1) $\mathrm{N}=30.2$ ) A figura ilustra a distribuição, em percentual, dos artigos que analisam as instituições políticas em perspectiva comparada pelas regiões do mundo analisadas. 3) O total ultrapassa 100\% porque um artigo pode analisar mais de uma região.

Fonte: Elaboração própria.

Como ilustra a Figura 9, a América Latina é a região mais analisada nos estudos sobre as instituições políticas com abordagem comparativa, seguida pela Europa Ocidental e a América do Norte. Em menor escala, aparecem Ásia, Europa Oriental, África e Oceania 9. Essa predominância da América Latina nos estudos comparativistas na ciência política, sobretudo para a área dos estudos institucionalistas, reflete a importância teórica e empírica da região para a disciplina. E essa importância pode estar associada aos acontecimentos da história recente dos países latino-americanos. Para ficar somente na área de instituições políticas, o que interessa para este artigo, o continente foi palco de vários processos de ruptura e instabilidade democrática nas últimas décadas, que trouxeram à tona inúmeros debates sobre quais instituições e sistemas de governo seriam mais benéficos à manutenção da democracia.

\section{CONCLUSÃO}

\footnotetext{
9 Essa relevância da América Latina para a política comparada também foi atestada por outros pesquisadores: Amorim Neto, 2010; Baquero e Gonzáles, 2013; Munck e Snyder, 2007.
} 
O objetivo deste artigo foi examinar os estudos sobre instituições políticas na ciência política brasileira por intermédio da sua produção acadêmica. Para tanto, foram analisados os artigos publicados pelos cientistas políticos brasileiros em cinco das principais revistas de ciências sociais do país: DADOS - Revista de Ciências Sociais, Novos Estudos, Revista Brasileira de Ciências Sociais, Opinião Pública e Brazilian Political Science Review. A pesquisa cobriu o período de 1966 a 2014, sendo classificados 235 artigos cujo tema principal eram as instituições políticas. Qual a proporção da área de instituições políticas sobre o total da produção da disciplina, como esses estudos distribuem-se no tempo, quais instituições são privilegiadas nos estudos, quais fontes e quais métodos de análise dos dados são utilizados, qual o escopo analisado e quais regiões do mundo são estudadas nas abordagens comparadas foram algumas das questões as quais este trabalho buscou responder.

Os achados deste artigo podem ser sumarizados da seguinte maneira: as instituições políticas predominam entre as áreas temáticas da ciência política brasileira, correspondendo a 1/4 do total da produção. Mas esse protagonismo teve início a partir da década de 1990, período que coincide com a redemocratização do país e a volta do livre funcionamento das instituições. Os estudos sobre o legislativo têm participação majoritária, e esse predomínio ocorreu a partir de meados dos anos 1990. Os estudos sobre os partidos políticos, mesmo constituindo uma das áreas mais tradicionais da ciência política brasileira, aparecem na segunda posição. No que diz respeito ao modo como esses temas foram estudados, houve uma clara mudança na orientação dos trabalhos: de um estilo de análise ensaístico-descritivo migrou-se para uma orientação empírica de pesquisa. $\mathrm{O}$ uso de fontes e métodos de análise de dados aumentou nas duas últimas décadas, embora ainda esteja fortemente concentrado em alguns deles (como os documentos e os dados oficiais e os métodos estatísticos). Quanto ao escopo das pesquisas, a análise exclusiva da política brasileira predomina em quase 3/4 dos casos, sendo que desses são as unidades nacionais as privilegiadas. Em relação às pesquisas comparadas, elas se voltam para os estudos sobre o Legislativo, os regimes democráticos e os sistemas eleitorais, prevalecendo como regiões de análise a América Latina e a Europa.

Assim, com a normalidade democrática no país, as instituições políticas ganharam posição privilegiada na ciência política, sobretudo as que dizem respeito ao resguardo da democracia, como o Legislativo e os partidos políticos. Essa proeminência vai ao 
encontro do processo de democratização que avançou nas décadas de 1980 e 1990 em outros países e provocou uma importante mudança no foco da análise em ciência política. O panorama teórico até então centrado nos atores políticos evoluiu para um programa centrado nas instituições políticas. Pode-se dizer que hoje a ciência política brasileira se dedica, em grande medida, a entender como funciona a democracia brasileira e suas instituições.

\title{
RESUMO
}

O objetivo do artigo é examinar os estudos sobre as instituições políticas na ciência política brasileira. A pesquisa analisa os artigos publicados, entre os anos de 1966 e 2014, em cinco revistas brasileiras: DADOS - Revista de Ciências Sociais, Novos Estudos, Revista Brasileira de Ciências Sociais, Opinião Pública e Brazilian Political Science Review. Os resultados mostram que as instituições políticas formam a área temática privilegiada para a ciência política brasileira e que esses estudos estão fortemente concentrados nos métodos quantitativos.

Palavras-chave: instituições políticas; ciência política brasileira; produção acadêmica.

\begin{abstract}
This paper aims to analyse the study of political institutions in brazilian political science. Research is based on the analyses of papers published, from 1966 to 2014, in five brazilian journals: Dados, Novos Estudos, Revista Brasileira de Ciências Sociais, Opinião Pública and Brazilian Political Science Review. Results have shown that political institutions are the privileged subject for brazilian political science and this studies are strongly focused on quantitative methods.
\end{abstract}

Keywords: political institutions; brazilian political science; academic production. 


\section{REFERÊNCIAS BIBLIOGRÁFICAS}

AMORIM NETO, Octavio. (2010), “A Política Comparada no Brasil: A Política dos Outros", in R. Lessa (org.), Horizontes das Ciências Sociais no Brasil: Ciência Política. São Paulo, ANPOCS, pp. 321-340.

BAQUERO, Marcello e GONZÁLES, Rodrigo Stumpf. (2013), “A Política Comparada na América Latina: Dilemas e Desafios”. Revista Debates, vol. 7, n³, pp. 111-126.

EASTON, David. (1985). "Political Science in the United States: Past and Present". International Political Science Review, vol. 6, n 1, pp. 133-152.

FIGUEIREDO, Argelina. (2010), "Executivo e Burocracia", in R. Lessa (org.), Horizontes das Ciências Sociais no Brasil: Ciência Política. São Paulo, ANPOCS, pp. $191-216$

LIMONGI, Fernando. (2010), “Estudos Legislativos”, in R. Lessa (org.), Horizontes das Ciências Sociais no Brasil: Ciência Política. São Paulo, ANPOCS, pp. 163-189.

MUNCK, Gerardo L. e SNYDER, Richard. (2007), "Debating the Direction of Comparative Politics: An Analysis of Leading Journals". Comparative Political Studies, vol. 40, $\mathrm{n}^{\circ} 1$, pp. 5-31.

NICOLAU, Jairo. (2010), "Partidos e Sistemas Partidários: 1985-2009”, in R. Lessa (org.), Horizontes das Ciências Sociais no Brasil: Ciência Política. São Paulo, ANPOCS, pp. 217-240.

PIERSON, Paul. (2007), "The Costs of Marginalization: Qualitatives Methods in the Study of American Politics”. Comparative Political Studies, vol. 40, n² 2, pp. 145-169.

SANTOS, M. L. (2008), “Teoria e Método nos Estudos sobre o Legislativo Brasileiro: Uma Revisão da Literatura no Período 1994/2005”. Boletim Informativo Bibliográfico, vol 66, pp. 65-89. 


\section{Anexo}

1. Ano da publicação

2. Revista

- Brazilian Political Science Review

- Dados

- Novos Estudos

- Opinião Pública

- Revista Brasileira de Ciências Sociais

3. Áreas temáticas

- Atores Políticos

- Eleições e Comportamento Político

- Estrutura Social

- Instituições Políticas

- Políticas Públicas

- Relações Internacionais

- Teoria e História do Pensamento Político

- Outros: trabalhos cujos temas não se enquadravam nas áreas temáticas já estabelecidas, tampouco apareciam em quantidade suficiente para justificar a inclusão de uma nova classificação.

4. Tipo de instituição política

- Federalismo (e descentralização)

- Partidos Políticos (e sistema partidário) 
- Sistema Eleitoral (e reforma política)

- Regime Político (ditadura, democracia e transição de regime)

- Forma de Estado (república ou monarquia)

- Sistema de Governo (presidencialismo, parlamentarismo ou sistema misto)

- Executivo (presidência, gabinetes, ministérios, burocracia e agências reguladoras)

- Legislativo (comissões, lideranças, produção legislativa, carreira parlamentar, atuação partidária e relação legislativo x executivo)

- Judiciário (Ministério Público, STF e Justiça Eleitoral)

- Constituição (processo constituinte; regras constitucionais e garantia de direitos)

5. Tipo de pesquisa

- Não Empírica: questões conceituais, teóricas ou de história do pensamento.

- Empírica: uso explícito de métodos de coleta e análise de dados, sejam eles qualitativos ou quantitativos.

- Análise Ensaístico-Descritiva: descrever eventos e organizações, sem utilizar métodos de coleta e análise de dados.

5. Fontes de dados

- Secundária: dados analisados por terceiros.

- Meios de Comunicação: jornais; revistas; telejornais.

- Documentos Oficiais: texto constitucional, projetos de lei; medidas provisórias; decretos de lei; relatórios; ofícios; regulamentos; programas de governo; diários oficiais.

- Documentos Não Oficiais: atas de reuniões; minutas; relatórios de assembleias; programas partidários; comunicações; boletins. 
- Estatísticas Oficiais: dados brutos oriundos de órgãos públicos, como IBGE, TSE, TRE's, Congresso; assembleias estaduais; câmaras municipais; prefeituras; governos estadual e federal; judiciário;

- Survey: para grupo específico ou de massa

- Entrevista

- Grupo Focal

- Experimento

6. Métodos de análise

- Estatística Descritiva: porcentagem; frequência; índices; escalas; teste de média; coeficiente de correlação;

- Estatística Multivariada: análise fatorial; análise de cluster; escala multidimensional; análise discriminante; análise de correspondência; análise de redes;

- Técnicas de Regressão (linear - simples ou múltipla; não-linear - log-linear, logit e probit; séries temporais)

- Modelos Formais

- Tipologia

- Análise de Conteúdo

- História Oral

\section{Escopo}

- Doméstico: apenas a política brasileira é analisada

- Comparado: a política de outro país é analisada 
8. Unidade

- Nacional

- Subnacional

- Grupo ou organização

9. Região

- América Latina

- América do Norte

- Europa Ocidental

- Europa Oriental

- Ásia

- África

- Oceania

Recebido em: 01/02/2016

Aprovado em: 17/05/2016 